\title{
The Prediction Model of Super Large Subsidence in High Water Table Coal Mining Areas Covered with Thick Unconsolidated Layer
}

\author{
Yueguan Yan, ${ }^{1}$ Weitao Yan $\mathbb{D}^{2},{ }^{2}$ Jibo Liu, $^{3}$ and Junting Guo ${ }^{4}$ \\ ${ }^{1}$ The College of Geoscience and Surveying Engineering, China University of Mining and Technology, Beijing 100083, China \\ ${ }^{2}$ School of Surveying and Land Information Engineering, Henan Polytechnic University, Jiaozuo, Henan 454003, China \\ ${ }^{3}$ College of Mining Engineering, Guizhou University of Engineering Science, Guizhou 551700, China \\ ${ }^{4}$ State Key Laboratory of Groundwater Protection and Utilization by Coal Mining, Beijing 102009, China
}

Correspondence should be addressed to Weitao Yan; yanweitao@hpu.edu.cn

Received 15 January 2021; Revised 25 January 2021; Accepted 30 January 2021; Published 30 March 2021

Academic Editor: Yi Xue

Copyright (C) 2021 Yueguan Yan et al. This is an open access article distributed under the Creative Commons Attribution License, which permits unrestricted use, distribution, and reproduction in any medium, provided the original work is properly cited.

In mining engineering, after the extraction of underground resources, the maximum surface subsidence is usually less than the mining thickness of coal seam. However, under the condition of thick loose layer, some special phenomena appear in surface subsidence, for example, the maximum surface subsidence value is greater than the mining thickness of coal seam. This special phenomenon cannot be predicted by traditional subsidence prediction methods. To solve this problem, by using the numerical simulation software Fast Lagrangian analysis of continua (Flac), we study the changing rules of subsidence with different strata lithology and unconsolidated layer thickness and reveal the formation mechanism of this law. The results show that the effect of the thick unconsolidated layer on the hard rock is greater than that of the soft rock. When the rock is soft, the unconsolidated layer moves as a whole following the bedrock during the whole mining process. The surface subsidence decreases approximately linearly with the thickness ratio increase of the unconsolidated layer to bedrock. However, when the rock is hard or medium hard, there are supporting structures formed inside the rock stratum, which has supporting effect on the overlying strata. The surface subsidence undergoes three proportional sections, first increases, then decreases, and finally increases with the thickness ratio increase of the unconsolidated layer to bedrock. Combined with these laws, based on the theory that the rock strata space can be completely compressed gradually, we derive the calculation method of surface subsidence under the condition of thick unconsolidated layer and apply it to practice. The results show that the prediction results are consistent with the actual situation and meet the engineering requirements. The research results can provide a reference for the subsidence prediction of similar conditions.

\section{Introduction}

The exploitation of underground coal resources has accelerated the economic development, but at the same time, it has also brought about great economic [1-3], environmental, and ecological damage problems [4-10], such as water accumulation on the subsidence area, cracks on the surface, settlement of residential land, and house damage, etc. For a long time, scholars have been studying and analyzing the mining subsidence under general conditions from the aspects of subsidence law [11-14], subsidence mechanism $[15,16]$, subsidence prediction [17-19], subsidence control method $[20,21]$ and obtained many research results, which have been applied in the field.

For describing the law of surface subsidence, the indexes of subsidence, slope, curvature, horizontal displacement, and horizontal strain are commonly used at present. Generally speaking, when mining horizontal or gently inclined seams, slope is the first derivative of subsidence, curvature is the second derivative of subsidence, horizontal displacement is proportional to subsidence, and horizontal strain is the first derivative of horizontal displacement [22]. It can be seen that 
subsidence is the main evaluation index. To express the degree of subsidence, the concept of subsidence factor is often used, especially in mining subsidence prediction. Subsidence factor is an important parameter, which indicates the ratio between the maximum subsidence value of the surface and the vertical thickness of the coal seam when the gob has reached the critical size.

$$
q=\frac{W_{O}}{M \cos \alpha}
$$

where $q$ is the subsidence factor, $W_{O}$ is the surface maximum subsidence value, $M$ is the mining thickness of coal seam, and $\alpha$ is the dip angle of coal seam.

Generally, the empirical value of subsidence factor can be determined according to the lithology of overlying strata, as shown in Table 1.

From the table, we can see that the subsidence coefficient is generally less than 1.0. That is, the surface subsidence value is less than the thickness of underground mining coal. However, through the analysis of a large number of measured data, it is found that under the condition of thick loose layer, there is a peculiar phenomenon: the surface maximum subsidence value is greater than the mining thickness of coal seam. In eastern and central China, there are many mine areas covered with the thick unconsolidated layer and the water table is high. Large-scale surface subsidence usually leads to the large area of surface water accumulation (Figure 1), which easily submerges the farmland and farmhouses, seriously damaging the local ecosystem.

Based on the measured data, the surface subsidence rule under the thick unconsolidated layer was studied. A variety of phenomena show that the surface subsidence rules with the thick unconsolidated layer have its particularity and the subsidence has been beyond the scope of traditional concepts. The maximum subsidence value of the surface is greater than the mining thickness of coal seam, the range of surface subsidence is wider, the horizontal movement value of some measuring points at the boundary is greater than the subsidence value, the active period is intense and concentrated, and the surface subsidence is stable for a long time (He et al., 1994). The research results under general conditions are not suitable for mining in thick unconsolidated layer.

This paper chose the Huainan mine area as the research object. Based on the numerical simulation method, with different lithology and different thickness ratio of unconsolidated layer and bedrock, the subsidence changing rules of different layers are studied. A revised formula for calculating subsidence is put forward accordingly. The research results have important theoretical and practical significance for enriching the theory of surface subsidence, protecting the surface buildings and ecological environment, reducing mining damage, improving the economic benefits of coal production enterprises, avoiding industrial and agricultural disputes, and realizing the sustainable development of coal industry.
TABLE 1: Empirical value of surface subsidence factor.

\begin{tabular}{lccc}
\hline Lithology & Hard & Medium hard & Soft \\
\hline Subsidence factor & $0.40-0.65$ & $0.65-0.85$ & $0.80-1.00$ \\
\hline
\end{tabular}

\section{Experimental Region and Research Method}

2.1. Experimental Region. The experimental region is located in Huaihe alluvial plain (Figure 2(a)). The mining area is flat. There are no faults in this area, and the geological structure is simple. The groundwater depth in this area is about $1 \mathrm{~m}$, which is typical in high water table coal mining areas. Coal seam 8 is a stable mineable coal seam with a thickness of $1.19-5.87 \mathrm{~m}$ and an average thickness of $3.25 \mathrm{~m}$. The roof is dominated by sandstone, while the floor is mudstone and sandy mudstone. Through the analysis of rock characteristics and physical mechanics properties, the comprehensive lithology of overlying strata is medium hard.

The panel 11118 is arranged in coal seam 8 . The length along the inclination and strike direction of panel 11118 is $162 \mathrm{~m}$ and $620 \mathrm{~m}$, respectively (Figure 2(b)). The average mining thickness is $5.0 \mathrm{~m}$, and the average mining depth is $550 \mathrm{~m}$. The unconsolidated layer thickness is about $300 \mathrm{~m}$, and the bedrock thickness is about $250 \mathrm{~m}$. The mining method adopts comprehensive mechanized coal mining with full height at one time, and the roof was managed by full caving method. The mining-induced damage to the ground structures is shown in Figure 3.

2.2. Research Method. Taking into account the geological and mining material of panel 11118, a two-dimension numerical model was built by using software Flac. The mining subsidence model has dimensions of length $=2000 \mathrm{~m}$ and height $=600 \mathrm{~m}$. The model strata are simplified, and there are six layers from bottom to top. The lowest strata are floor mudstone with the thickness of $45 \mathrm{~m}$. Overlying the strata is coal seam, and the thickness is $5 \mathrm{~m}$. The immediate roof is sandstone with $10 \mathrm{~m}$ thickness. Above the immediate roof are siltstone and fine sandstone, and the thickness is $90 \mathrm{~m}$ and $150 \mathrm{~m}$, respectively. The top is unconsolidated layer with the thickness of $300 \mathrm{~m}$. The comprehensive lithology of overlying strata is medium hard. Coal seam dip angle is $0^{\circ}$. The value of panel length is $800 \mathrm{~m}$. This model assumes that the rock failure obeys Mohr-Coulomb strength criterion. The numerical simulation design is showed in Figure 4 . In this paper, $H_{s}$ is the thickness of the unconsolidated layer, $H_{j}$ is the thickness of bedrock, and $H$ is the mining depth.

For comparison and analysis, the other two models were built based on the prototype of medium-hard rock numerical model. The models only change the physical mechanics parameters, and the strata geometry size and name remain the same as the prototype. According to the knowledge of rock mechanics, the harder the lithology is, the greater the density, elasticity module, Poisson ratio, tensile strength, internal frictional angle, and cohesive force are. Therefore, taking medium hard as the prototype, the parameters of soft rock stratum are 0.9 times of medium hard, while those of hard rock stratum 

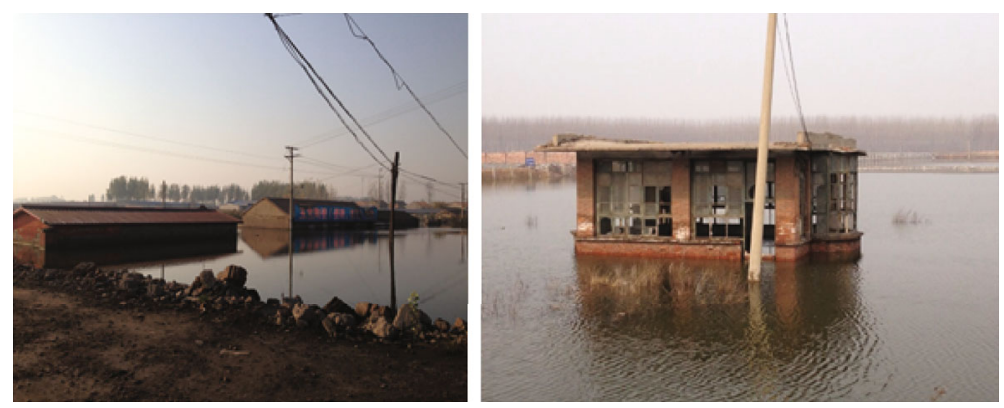

Figure 1: Surface water accumulation.

are 1.1 times. The soft, medium-hard, and hard models with different physical mechanics parameters are shown in Table 2.

\section{Experimental Results and Analysis}

\subsection{Subsidence Changing Rules of Different Lithology and} Strata under Thick Unconsolidated Layer. The model was mined $5 \mathrm{~m}$ height at one time, and the excavation dimension was $800 \mathrm{~m}$. The maximum subsidence value and subsidence factor of different layers with soft, medium-hard, and hard rock could be obtained from immediate roof to surface with $50 \mathrm{~m}$ interval value. Subsidence curves of immediate roof, unconsolidated layer and bedrock interface (hereinafter referred to as interface in this paper), and surface with different lithology are shown in Figure 5.

Changing curves are shown in Figure 6 of subsidence factor of different layers in the soft, medium-hard, and hard lithology strata and unconsolidated layer.

Figure 6 indicates that no matter the rock lithology whether soft or hard, the subsidence factor decreases linearly with the increase of vertical distance from the layer to goaf.

If the overlying strata are hard lithology, in the process of the rock damage and subsidence, the fracture zones not only produce the vertical cracks of rock but also produced a large number of bed separation cracks along the strata level. These fissures and fractures form a large amount of compressible space in bedrock. Under the action of thick unconsolidated layer, these compressible spaces are recompressed, and the compression is large. This causes the subsidence factor in bedrock to decrease rapidly with the increase of vertical distance from the layer to goaf.

If the bedrock is soft lithology, overburden is not easy in order to produce the bed separation cracks in the process of the rock subsidence and less compressible space formed. Under the action of the thick unconsolidated layer, the compressible spaces are recompressed, but the compression is smaller than the hard rock. Therefore, the subsidence factor in soft bedrock decreases slower than that in hard rock with the increase of vertical distance from the layer to goaf.

Therefore, there is more compressible space in hard rock than in soft rock, and the subsidence factor of hard rock is less than that of the soft rock under the same condition.
When the lithology is medium hard, the change of subsidence factor falls in between.

However, the unconsolidated layer variation has nothing to do with the strata lithology and the changing trend of unconsolidated layer is the same. All of them move as a whole. The subsidence factor of unconsolidated layer inside changes little and decreases linearly with the increase of vertical distance from bedrock to surface. The change range of unconsolidated layer is close to the soft rock. Therefore, it is stated that the unconsolidated layer has a certain expansion, which can play a supporting role to the surface.

3.2. Subsidence Changing Rules of Surface and Interface with Different Unconsolidated Layer Thickness. To study the effect of different unconsolidated layer thickness on the subsidence factor, keeping the rock size, thickness of coal seam, mining dimension, nature of unconsolidated layer, and the rock lithology conditions unchanged, the thickness of unconsolidated of $100 \mathrm{~m}, 200 \mathrm{~m}, 400 \mathrm{~m}, 500 \mathrm{~m}$, and $600 \mathrm{~m}$ was simulated.

Starting from the direct roof of coal seam to the surface, taking $50 \mathrm{~m}$ as interval, the variation curves of subsidence factors of soft, medium-hard, and hard rock strata and different thickness of loose strata are drawn. As shown in Figure 7, the direct roof is $0 \mathrm{~m}$ from the vertical distance of goaf, and the interface of loose strata and bedrock is $250 \mathrm{~m}$ from the vertical distance of goaf. The maximum vertical distance in abscissa means the position of the surface.

From the analysis of Figure 7, it can be seen that the subsidence factors of all layers in rock mass and loose stratum decrease with the increase of vertical distance from the layer to goaf, and the variation range is different. With the increase of the thickness of unconsolidated layer, the variation range of subsidence factor with different lithological strata is different. When the bedrock is weak, the subsidence factor of the interface between the unconsolidated layer and the bedrock changes slightly. When the thickness of the unconsolidated layer increases from $200 \mathrm{~m}$ to $600 \mathrm{~m}$, the subsidence factor is about $0.90-0.92$. Nevertheless, when the bedrock is hard, the subsidence factor of the interface changes greatly when the thickness of the unconsolidated layer increases from $100 \mathrm{~m}$ to $600 \mathrm{~m}$, from 0.38 to 0.82 . Such a wide range of changes indicates that the increase of the unconsolidated layer thickness increases the load on the underlying bedrock 


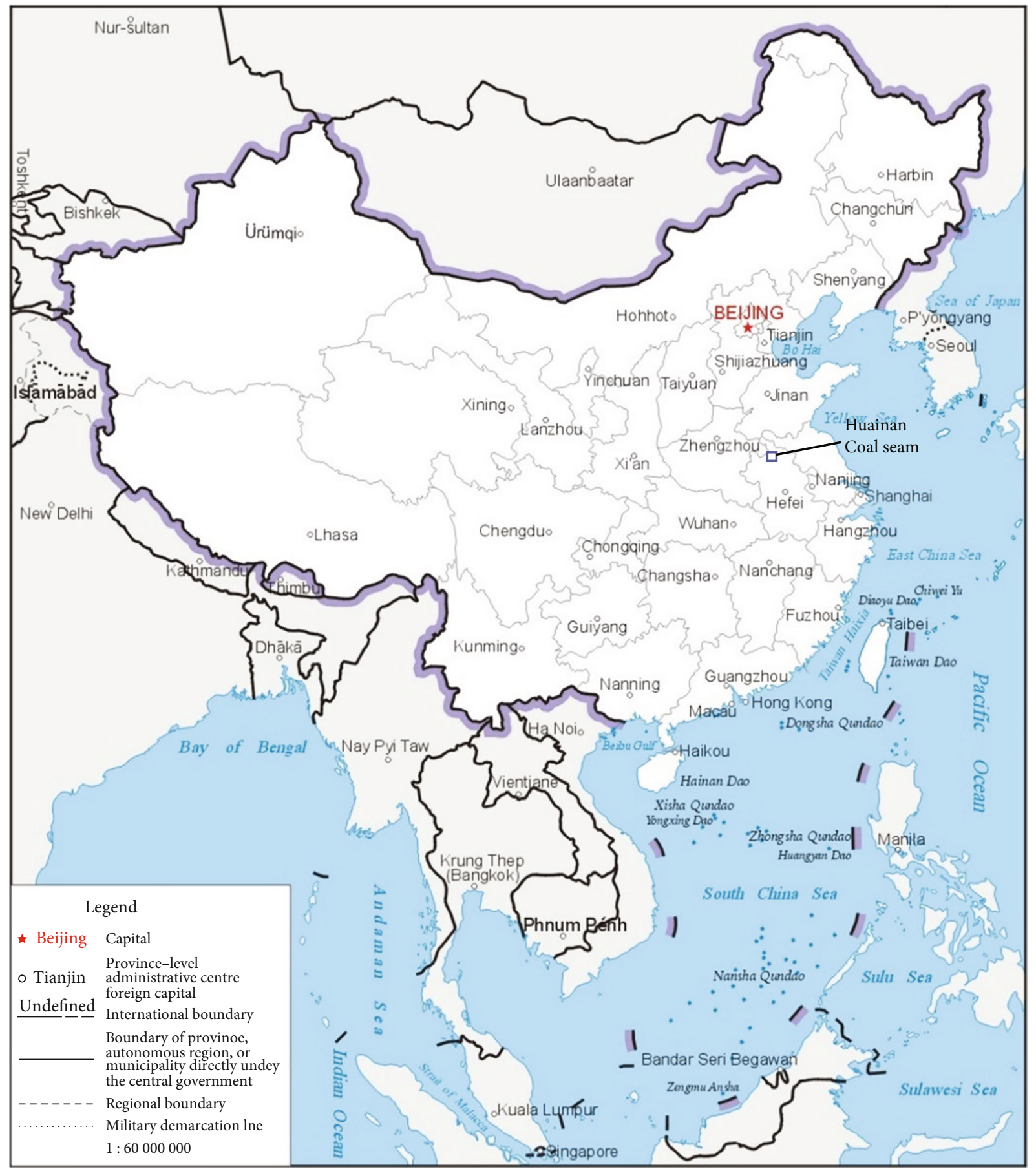

(a)

Figure 2: Continued. 


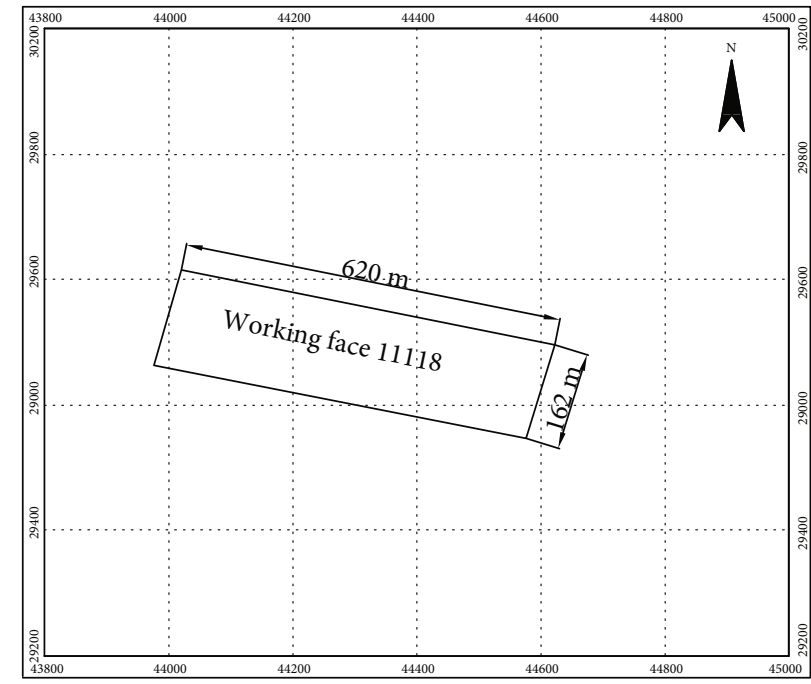

(b)

Figure 2: Study site. (a) Location of Huainan coal mine in China, the original image is quoted from national platform for common geospatial information services; (b) roadway layout of 11118 working face.

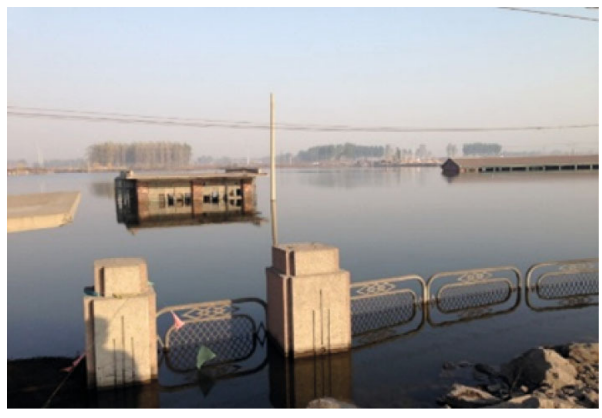

(a) Surface water ponding

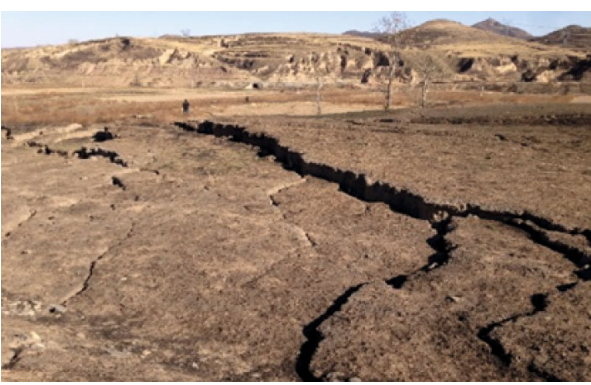

(b) Surface crack

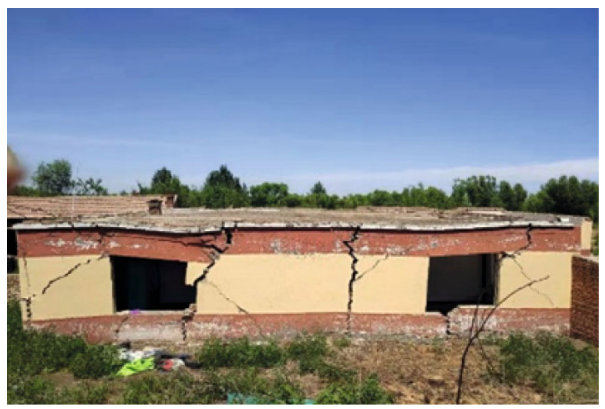

(c) Damage to the house

FIGURE 3: Problem map induced by mining subsidence.

and greatly increases the space compression of the bedrock.

\section{Discussion}

4.1. Subsidence Mechanism Analysis. For further analysis, the maximum subsidence values and subsidence factors of surface and interface are calculated based on different lithology and thickness ratios of unconsolidated layer to bedrock. The variation curves are drawn in Figure 8.
Combines with Figure 8, we can reveal the subsidence mechanism from two dimensions of lithology and thickness ratio of unconsolidated layer to bedrock.

(1) When the bedrock lithology is weak, the subsidence factor of the interface is larger, and the change range is smaller than others (Figure 9). This indicates that after the soft rock is affected by mining, there is almost no supporting structure and compressible space formed in the bedrock. The main performance 


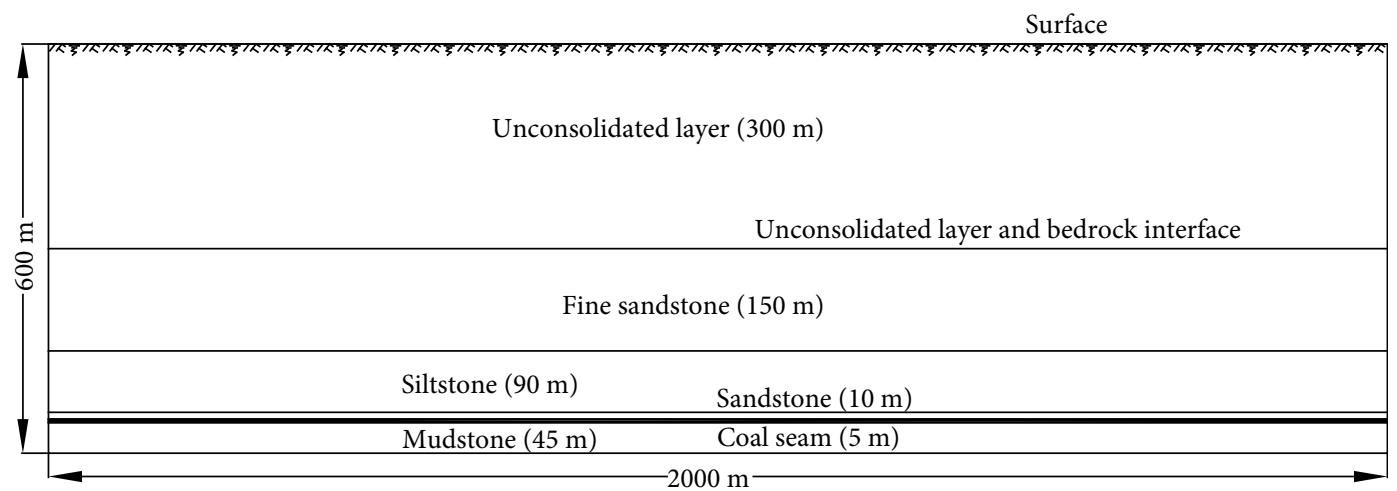

FIgURE 4: Numerical simulation design.

of overlying strata is overall subsidence. The increase of unconsolidated layer thickness is equivalent to the increase of mining depth, which leads to the surface subsidence factor approximately linearly reduced with the increase of thickness ratio

(2) When the bedrock lithology is hard or medium hard, there is more supporting structure and compressible space formed within the strata. The increase of unconsolidated layer thickness is equivalent to the increase of load on bedrock, which leads to the compressible space in the bedrock gradually reduced. Moreover, the larger the unconsolidated layer thickness is, the greater the reduction degree of compressible space within the bedrock is. Through the experiment, it is found that the subsidence factor of the interface increases linearly with the increase of the thickness ratio. However, the surface subsidence factor has certain fluctuation, which can be roughly divided into three proportional sections

(a) Proportional section one: when the thickness of the unconsolidated layer is less than 1.2 times that of the bedrock (Figure 10(a)). With the increase of the unconsolidated layer thickness, the load on the bedrock increases gradually, and the compressible space with poor structure inside the stratum is compressed. At this time, the subsidence factors of the surface and the interface have the same trend, both of which increase. However, the total supporting force of supporting structure in bedrock is greater than the pressure of overlying loose layer and its own gravity

(b) Proportional section two: when the unconsolidated layer thickness is between 1.2 and 2.0 times that of the bedrock (Figure 10(b)). With the increase of the unconsolidated layer thickness, the load on the bedrock increases gradually with the increase of the unconsolidated layer thickness. However, due to the existence of strong braced structure, the increase of subsidence factor at the interface is smaller than that at proportional section one. At the same time, the increase of unconsolidated layer thickness is equivalent to the increase of mining depth, resulting in the decrease of surface subsidence factor. That is, the subsidence factor of interface and surface has opposite development trend at this proportional section

(c) Proportional section three: when the unconsolidated layer thickness is larger than 2.0 times that of the bedrock (Figure 10(c)). With the increase of unconsolidated layer thickness, the load on the bedrock becomes larger, and the strong braced structure inside the stratum is collapsed. At this time, the surface subsidence factor increases again, and the change trend of the interface subsidence factor is the same again

4.2. Inversion Method of Subsidence Factor under the Condition of Thick Unconsolidated Layer. We use the probability integral method to predict overburden and surface subsidence. The probability integral method is an influence function method, which is based on the extraction of the infinitesimal elements of an area. The surface subsidence induced by the extraction of a unit coal seam is as follows:

$$
W_{e}(x)=\frac{1}{r} e^{-\pi\left(x^{2} / r^{2}\right)} .
$$

If we integrate the whole space, the calculation formula for any surface point subsidence is as follows:

$$
W(x, y)=\frac{M q \cos \alpha}{r^{2}} \int_{0}^{D_{3}} \int_{0}^{D_{1}} e^{-\pi\left(\left((x-s)^{2}+(y-t)^{2}\right) / r^{2}\right)} d t d s,
$$

where $W(x, y)$ is the surface subsidence value of point $(x, y), M$ is the mining height, $q$ is the subsidence factor, $\alpha$ is the inclination angle of coal seam, $r$ is the major influence radius, and $D_{3}$ and $D_{1}$ are the length and width of the panel, respectively.

The predicted results mainly include subsidence $(w)$, inclination $(i)$, curvature $(k)$, horizontal displacement $(u)$, 


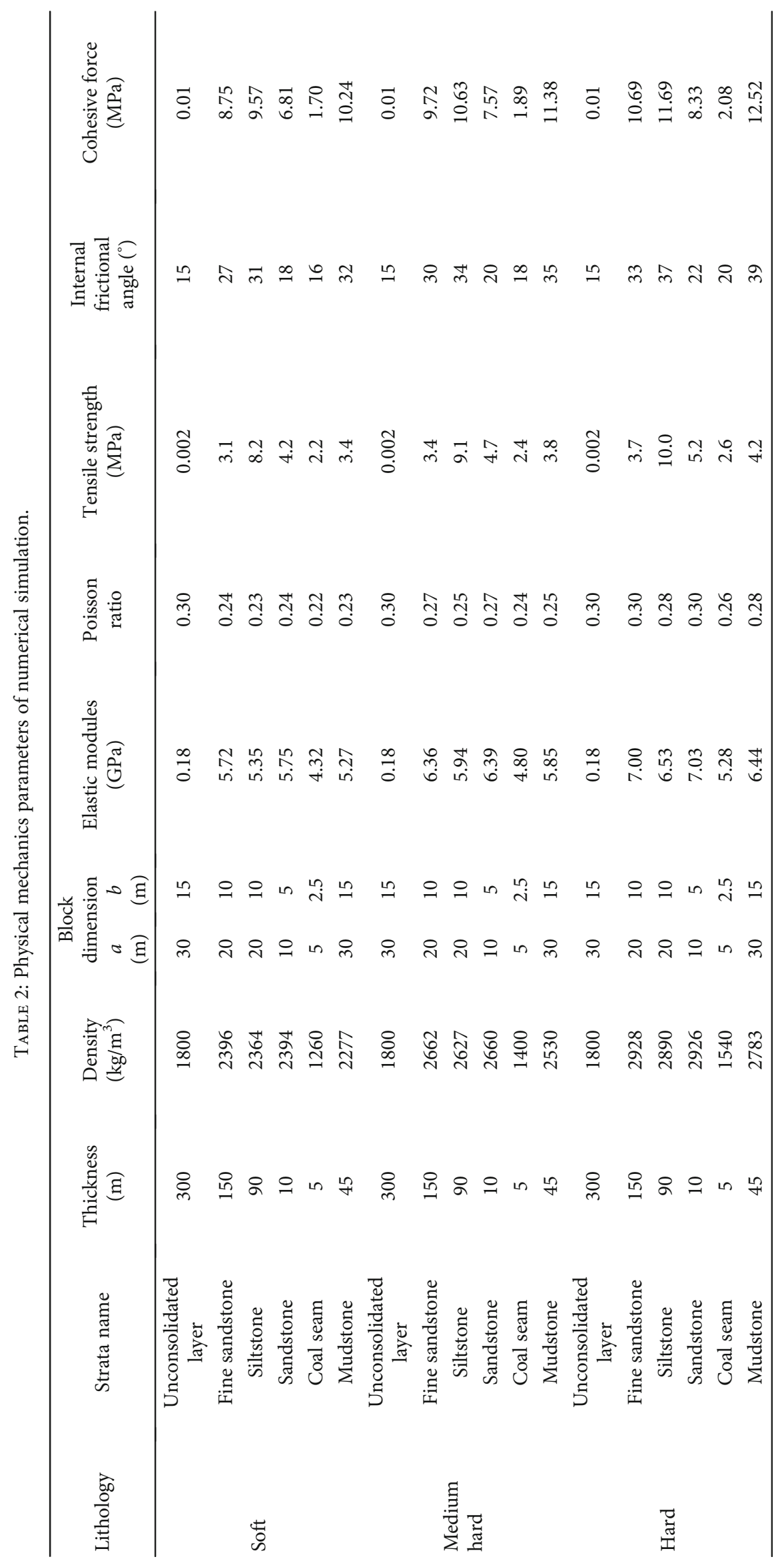



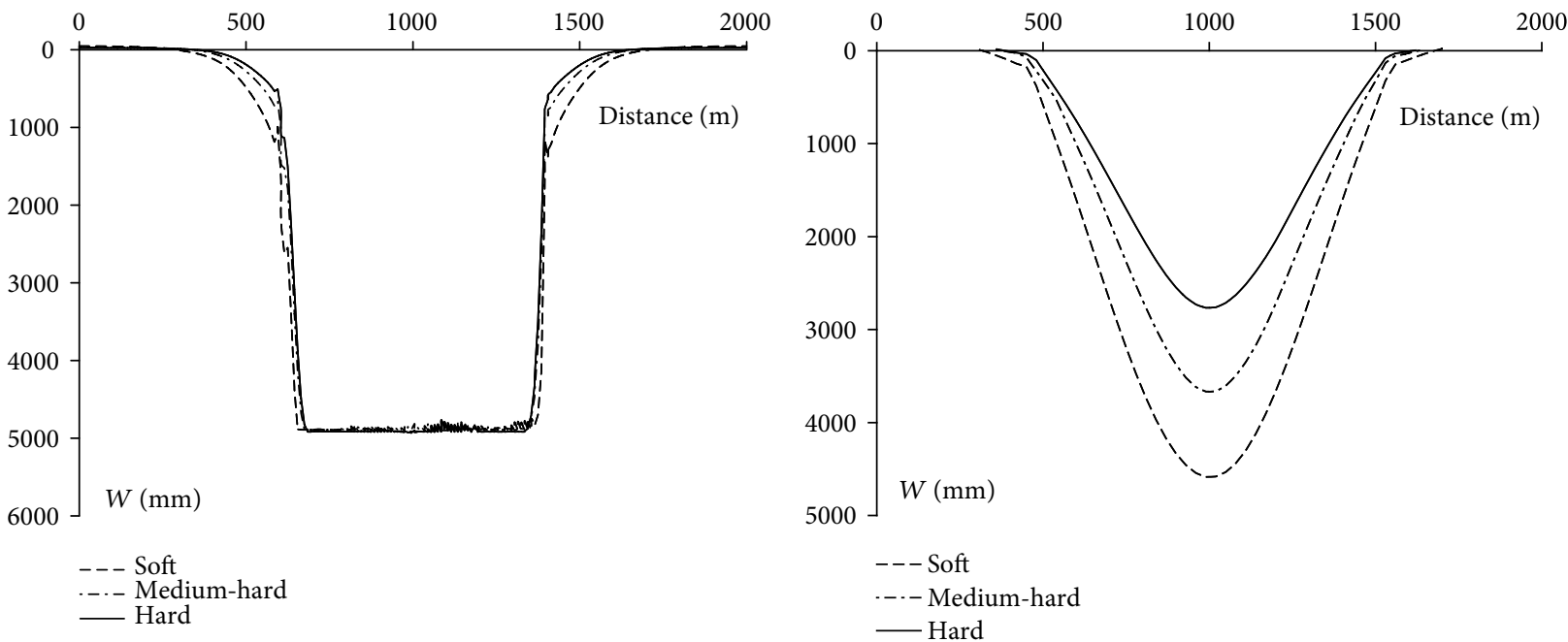

(a) $H=0 \mathrm{~m}$ (immediate roof)

(b) $H=250 \mathrm{~m}$ (interface)

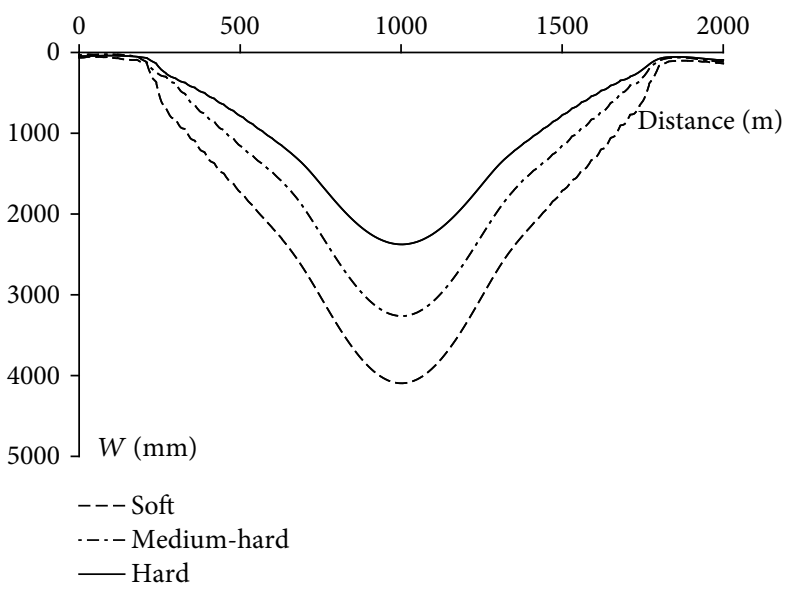

(c) $H=550 \mathrm{~m}$ (surface)

FIgURE 5: Subsidence curves of different layers with different lithology.

and horizontal deformation $(\varepsilon)$. Among them, inclination, curvature, horizontal displacement, and horizontal deformation can be derived from subsidence. Therefore, subsidence is the most important.

$$
\begin{aligned}
i_{12} & =\frac{w_{1}-w_{2}}{l_{12}}, \\
k & =\frac{i_{12}-i_{23}}{0.5\left(l_{12}+l_{23}\right)}, \\
u & =b r i, \\
\varepsilon & =b r k .
\end{aligned}
$$

Subsidence is mainly determined by the parameter of subsidence factor. Therefore, this paper mainly studies the calculation method of subsidence factor under the condition of thick loose layer. In general, the law of overburden subsidence and surface subsidence is mainly determined by bedrock, and the subsidence factor can be selected according to the traditional experience (Table 1). However, under the condition of thick unconsolidated layer, the subsidence law is determined by both bedrock and unconsolidated layer; the surface shows specificity. Therefore, we need to consider the comprehensive influence of rock and soil on the subsidence to study the subsidence factor. Thus, we take the continuous corrective effect of the unconsolidated layer on the subsidence into consideration and deduced the calculation formula of the subsidence factor under the condition of thick unconsolidated layer.

Given the subsidence correction factor is $k_{\mathrm{s}}$ (Figure 11), which is induced by the multifactor comprehensive influence of unconsolidated layer, for an area element $\Delta s$ at the maximum subsidence position of the interface, after subsidence, the bedrock provides the compressible space $m q_{j} \Delta s$ for the unconsolidated layer. Assume that the compressible space is compressed $n$ times, and it is completely compacted.

After the compressible space is compressed for the first time, the new subsidence space $m q_{s}^{\prime} \Delta s$ appears on the ground surface, as follows:

$$
m \times q_{j} \times \Delta s=k_{s} \times m \times q_{S}^{\prime} \times \Delta s,
$$




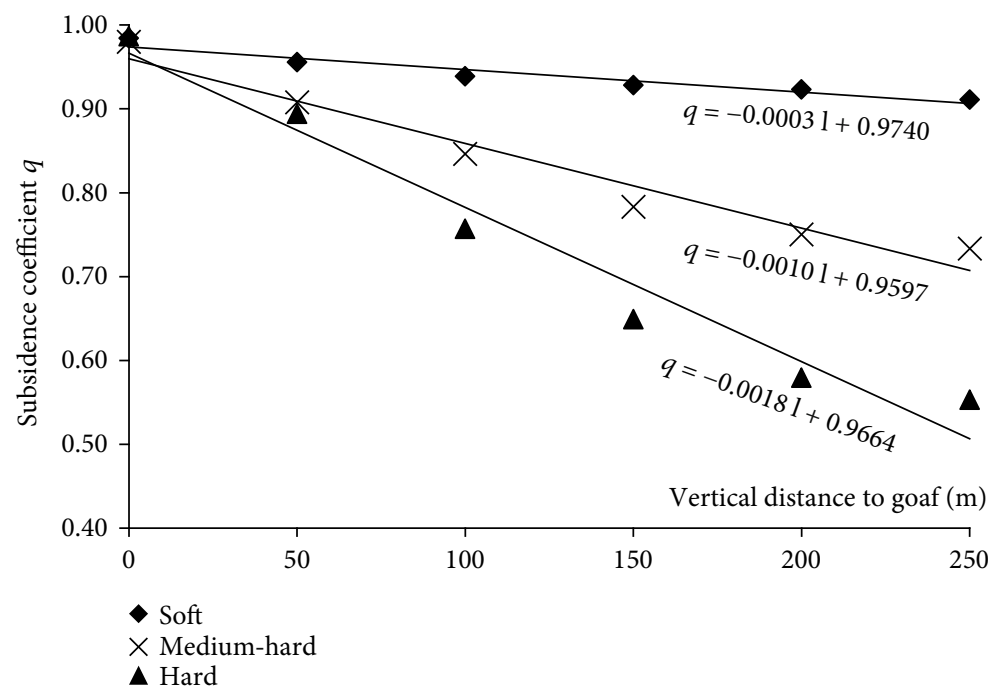

(a) Bedrock internal

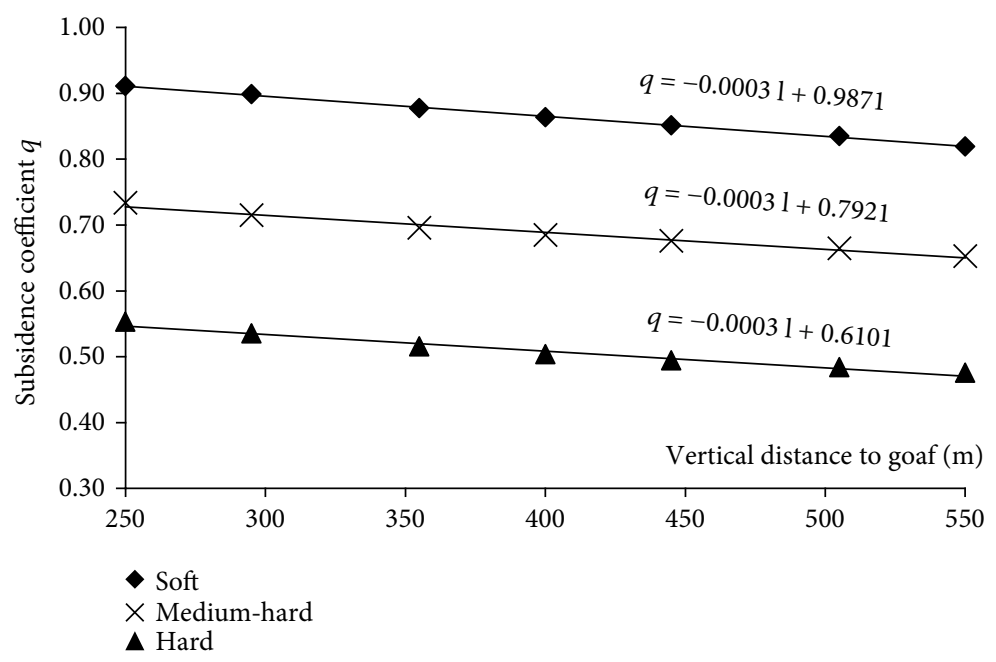

(b) Unconsolidated layer internal

Figure 6: Changing curves of subsidence factor in soft, medium-hard, and hard lithology strata.

namely,

$$
m \times q_{j}=k_{s} \times m \times q_{s}^{\prime}
$$

After the compressible space is second compressed, the subsidence space $m q_{s}^{\prime \prime} \Delta s$ appears on the ground surface, as follows:

$$
m \times q_{s}^{\prime}=k_{s} \times m \times q_{s}^{\prime \prime} .
$$

Similarly, after the compressible space is compressed $n$ times, the subsidence space $m q_{s} \Delta s$ appears on the ground surface, as follows:

$$
m \times q_{s}^{n-1}=k_{s} \times m \times q_{s} .
$$

Combined with the formula above,

$$
m \times q_{j}=k_{s}^{n} \times m \times q_{s}
$$

namely,

$$
q_{s}=\frac{q_{j}}{k_{s}^{n}}
$$

where $m$ is the mining thickness $(\mathrm{m}), H_{s}$ is the unconsolidated layer thickness (m), and $n$ is the compress time.

Now calculate $n$. The subsidence correction factor of unconsolidated layer is $k_{s}$ and $i$ is the compress time.

$$
h_{i}=\frac{m q_{j} \cos \alpha}{k_{s}^{i}} .
$$




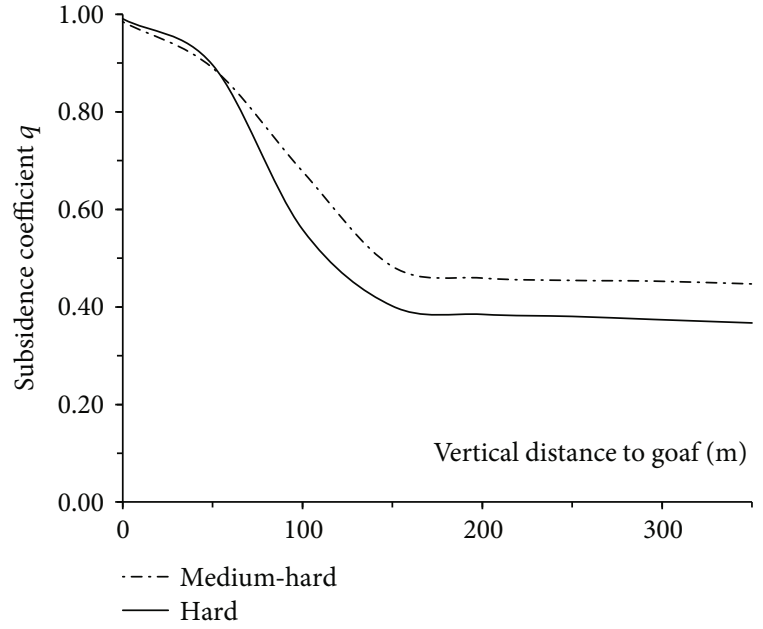

(a) $H_{s}=100 \mathrm{~m}$

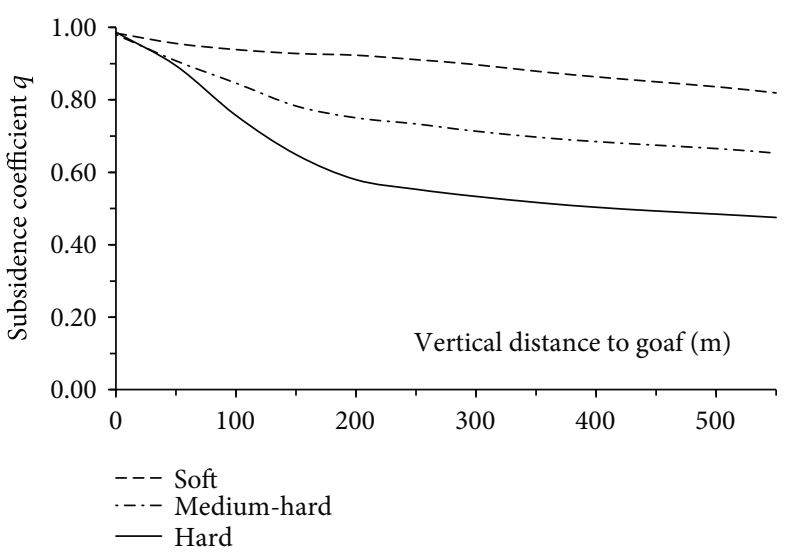

(c) $H_{s}=300 \mathrm{~m}$

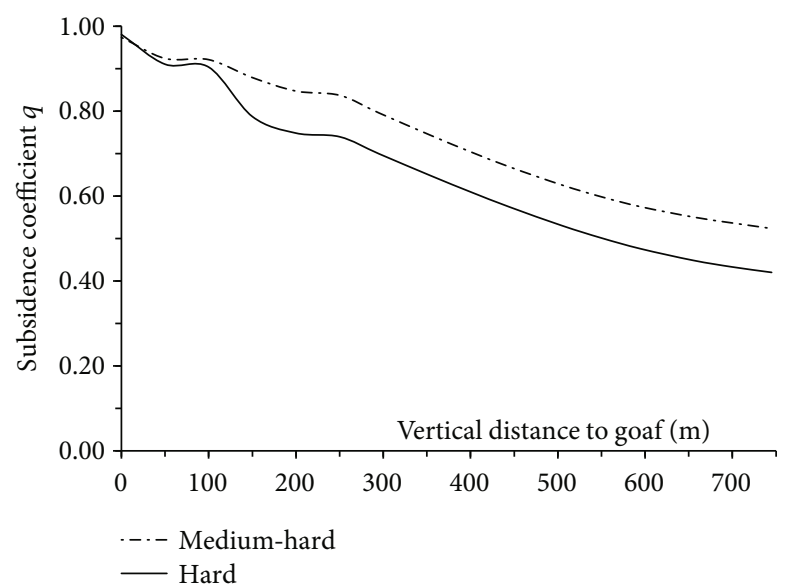

(e) $H_{s}=500 \mathrm{~m}$

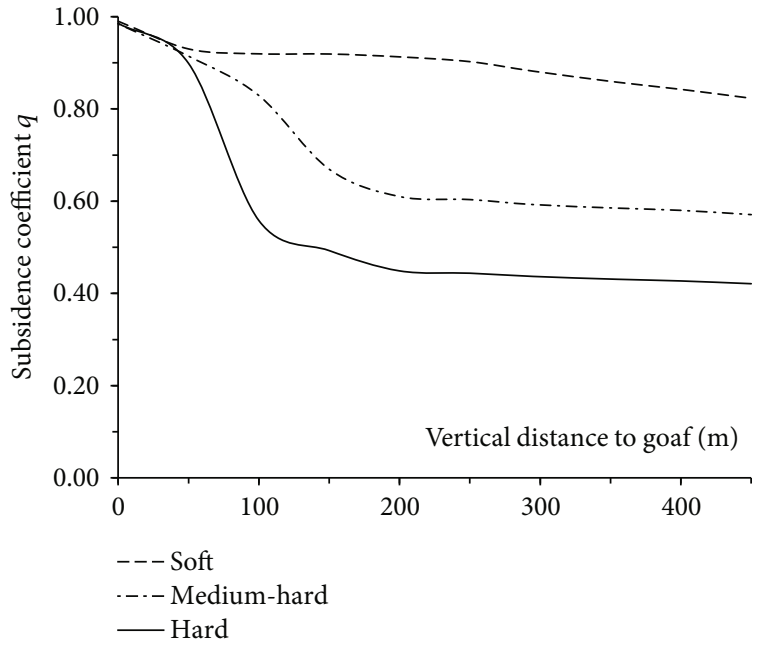

(b) $H_{s}=200 \mathrm{~m}$

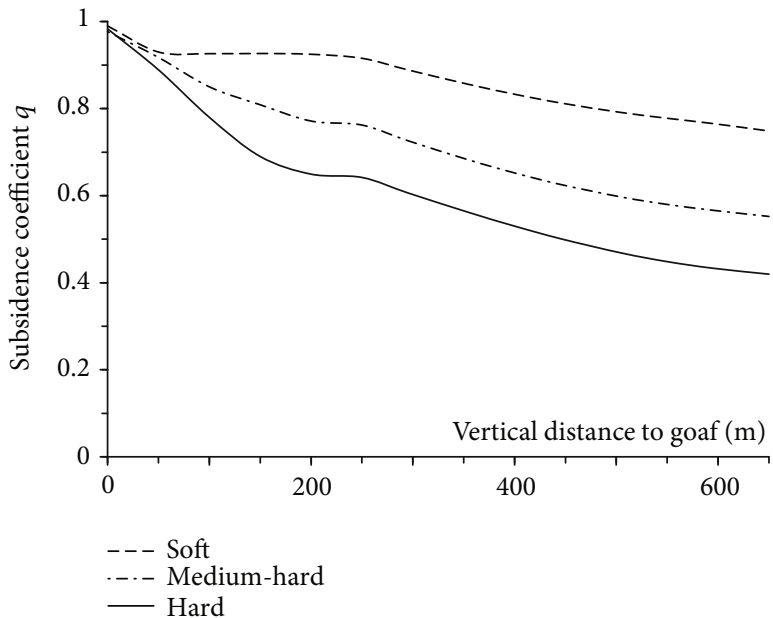

(d) $H_{s}=400 \mathrm{~m}$

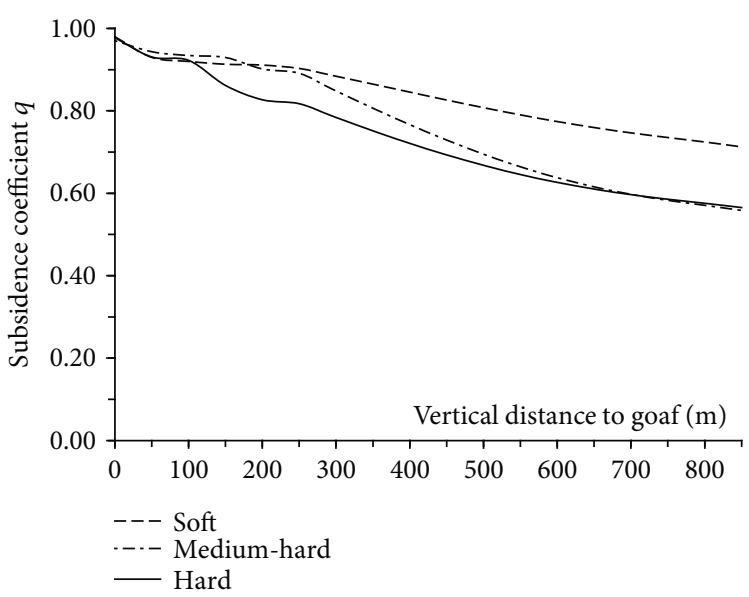

(f) $H_{s}=600 \mathrm{~m}$

FiguRE 7: Subsidence factor changing curves of soft, medium, and hard lithology strata and different thickness of unconsolidated layers.

After the compressible space is compressed $n$ times,

$$
h=h_{1}+h_{2}+\cdots+h_{n}
$$

namely,

$$
h=\frac{m q_{j} \cos \alpha}{k_{s}-1}\left(1-\frac{1}{k_{s}^{n}}\right) .
$$




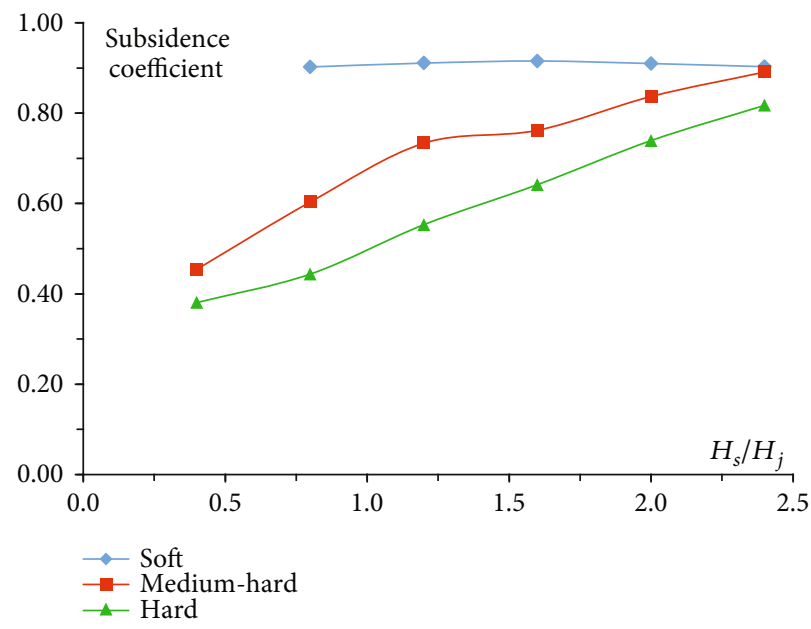

(a) Interface

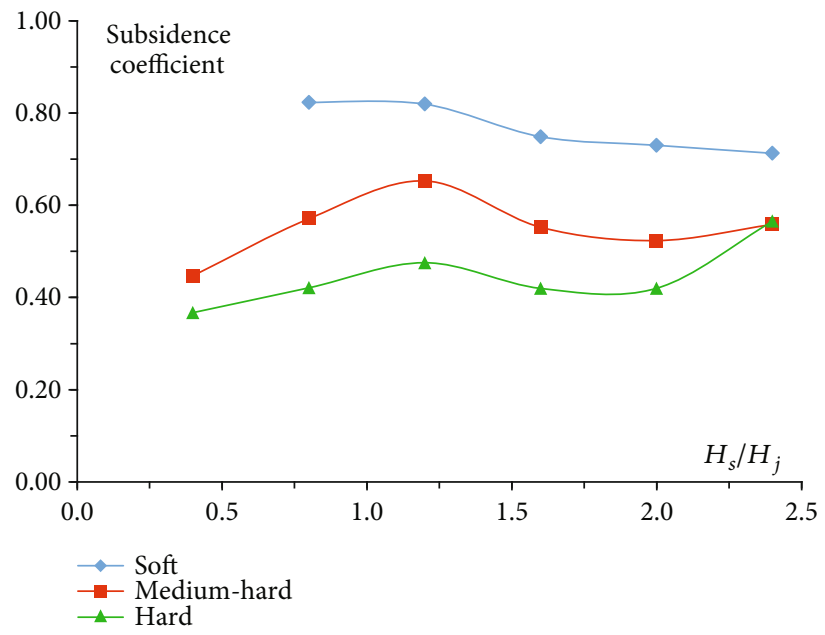

(b) Surface

Figure 8: Surface and interface subsidence factor change curves with different thickness ratio of different lithology bedrock and unconsolidated layer.

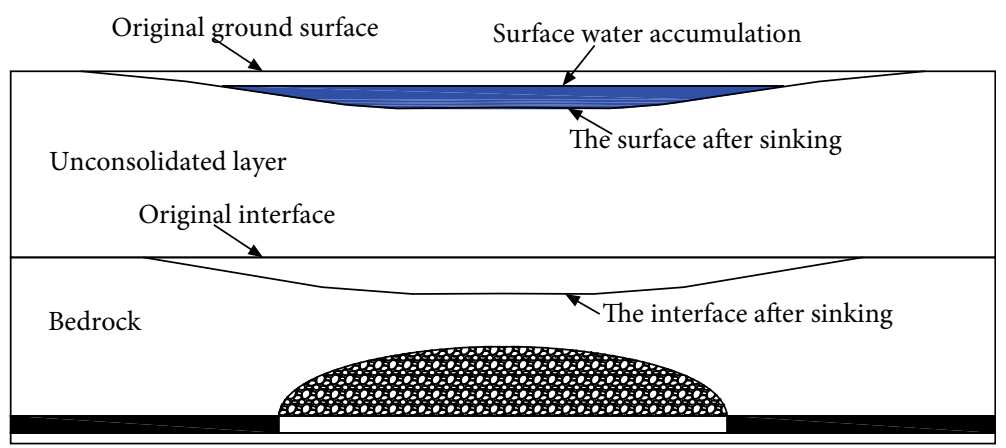

FIGURE 9: Schematic diagram of overburden subsidence of soft rock.

Let $h$ be equal to $H_{s}$. So

$$
H_{s}=\frac{m q_{j} \cos \alpha}{k_{s}-1}\left(1-\frac{1}{k_{s}^{n}}\right) .
$$

Therefore, the relationship of subsidence correction factor $k_{s}$ and compress times $n$ is

$$
n=\frac{\ln \left[1-\left(H_{s} / m q_{j} \cos \alpha\right)\left(k_{s}-1\right)\right]}{\ln \left(1 / k_{s}\right)},
$$

where $\alpha$ is the dip angle of coal seam.

To simplify the calculation, $n$ can be obtained by the following formula:

$$
n=\frac{H_{s}}{m q_{j} \cos \alpha}
$$

Therefore, the surface subsidence factor $q_{s}$ is

$$
q_{s}=\frac{q_{j}}{k_{s}^{n}}
$$

4.3. Determination of Subsidence Factor. The surface subsidence is the appearance of the mining influence on the surface under the joint action of bedrock and loose layer. The mining influence first propagates in the bedrock, then transfers to the loose layer through the interface, and finally to the surface. To accurately invert the surface subsidence factor, it is necessary to study the propagation law of mining influence within the bedrock, determining the subsidence factor at the interface and then to study the propagation law of the mining influence within the unconsolidated layer, determining the surface subsidence factor.

4.3.1. For Interface. According to the above analysis, when the bedrock is medium-hard or hard lithology and the thickness ratio of unconsolidated layer to bedrock is larger than 2.0, the supporting structure in the rock mass is gradually collapsed, which leads to the increase of interface subsidence factor. This phenomenon can be regarded as lithologic softness. Therefore, when predicting any point subsidence in the interior space of bedrock under thick unconsolidated layer, especially in medium-hard and hard lithology, the interface subsidence factor cannot be calculated according to the conventional experience. Referring to the regulation, 


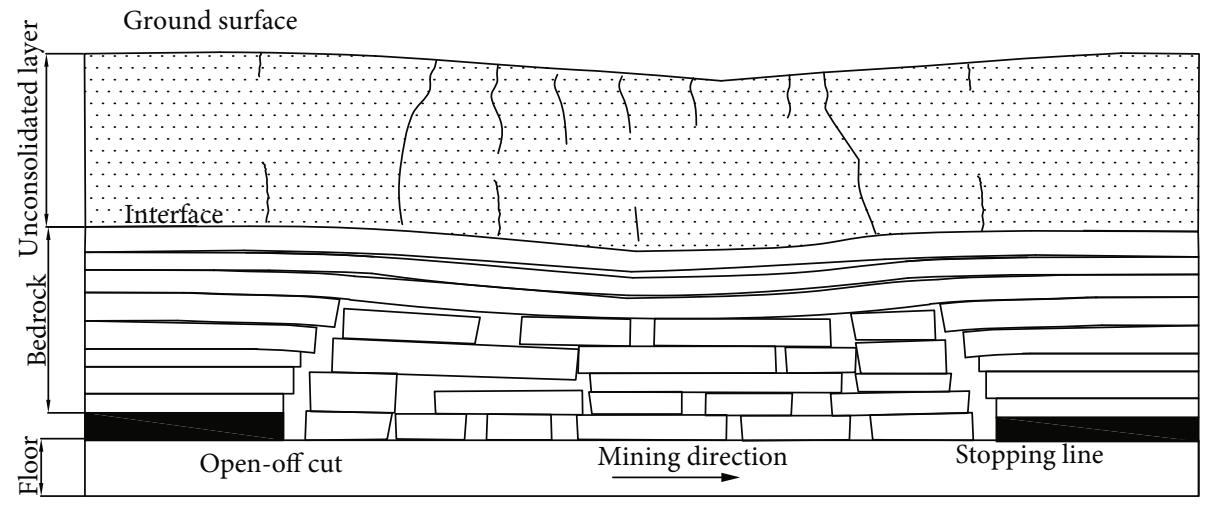

(a) $H_{s} / H_{j} \leq 1.2$

Ground surface

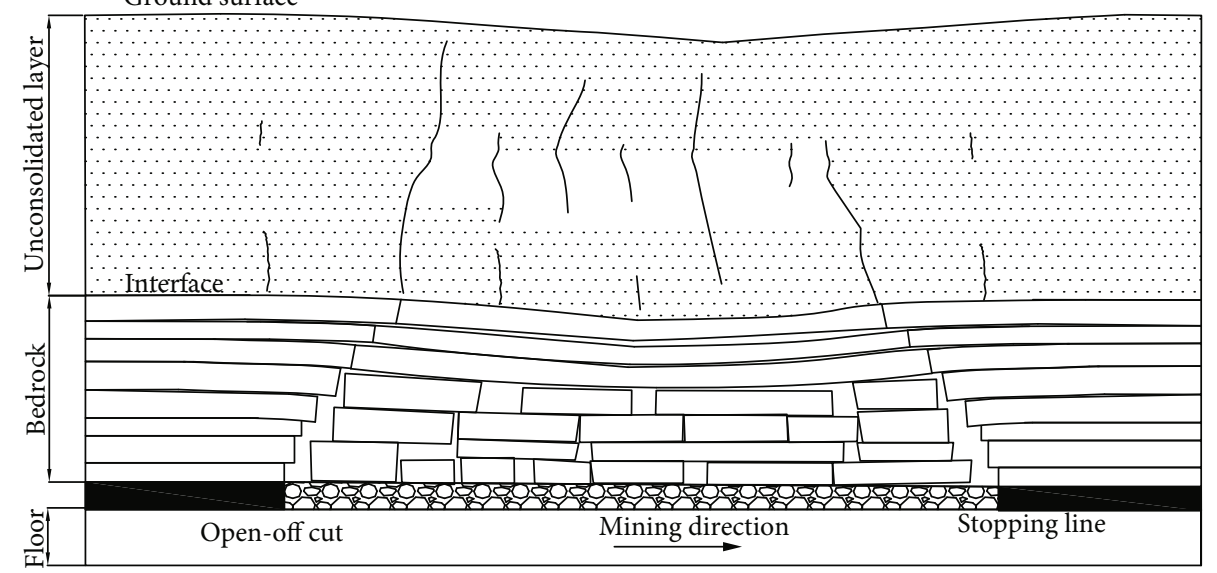

(b) $1.2<H_{s} / H_{j} \leq 2.0$

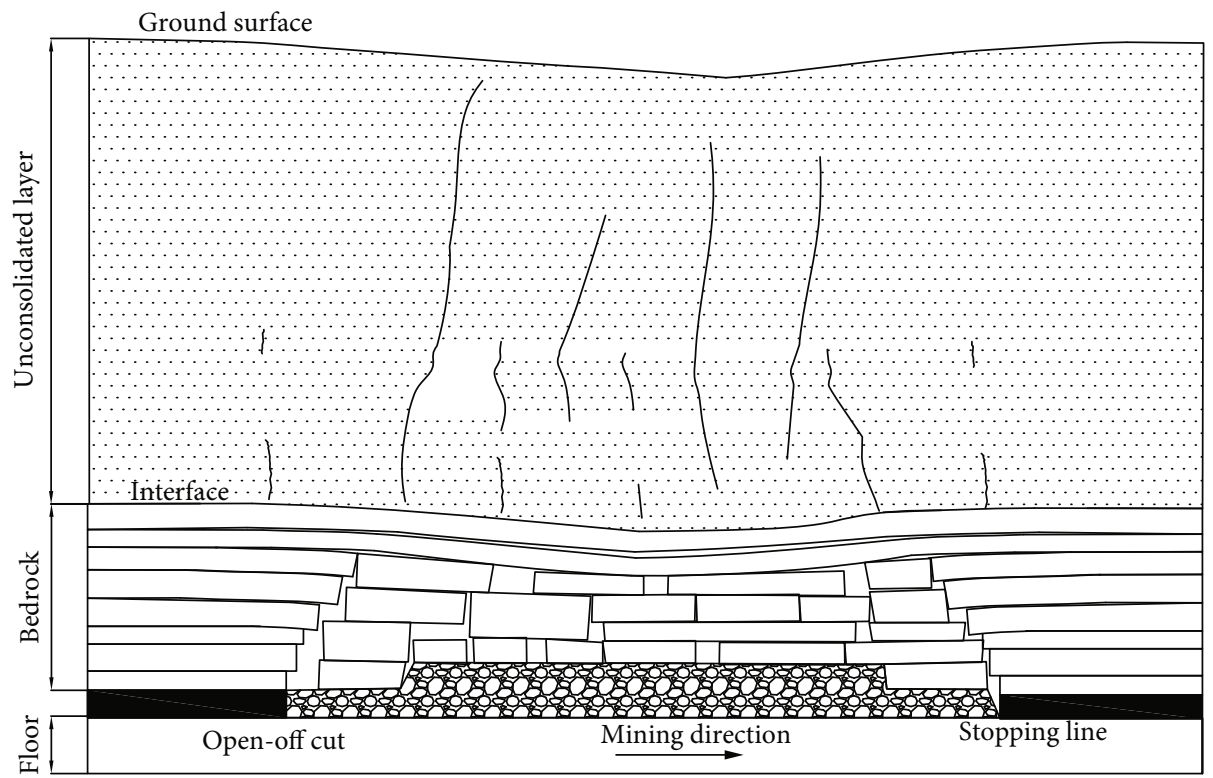

(c) $H_{s} / H_{j}>2.0$

Figure 10: Schematic diagram of overburden subsidence of hard or medium-hard rock. 


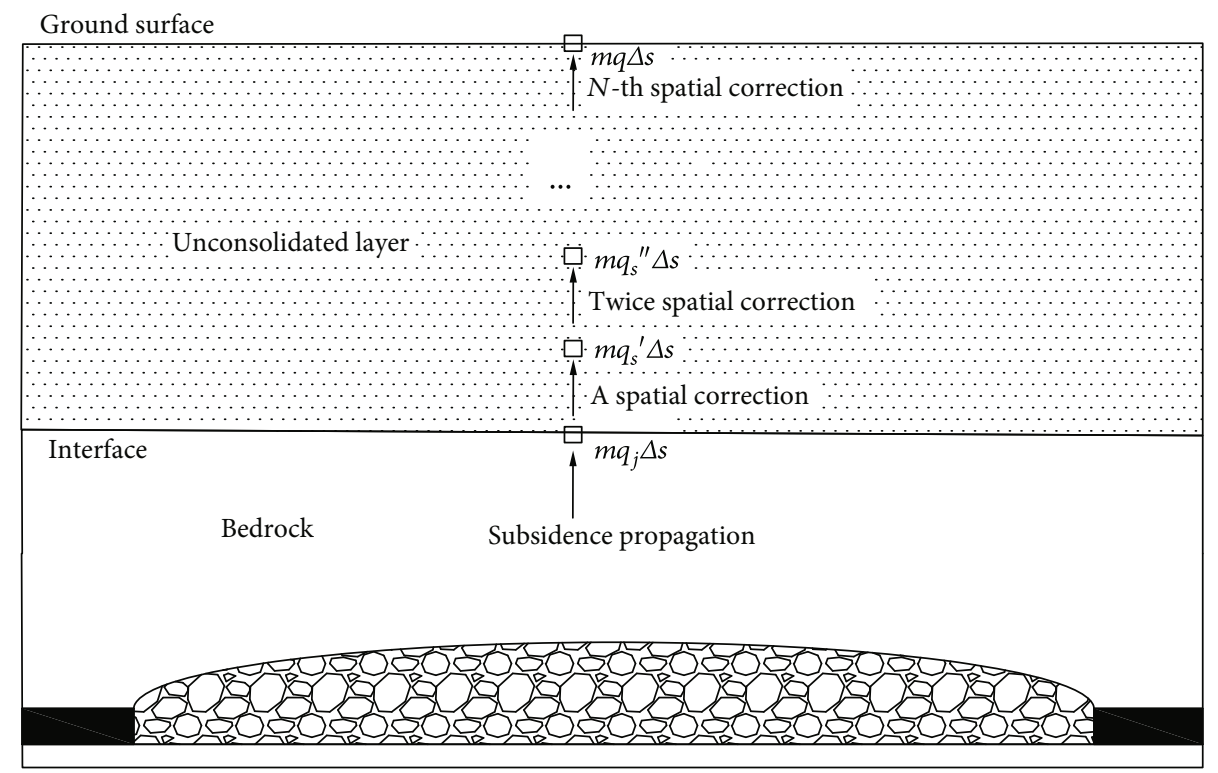

FIGURE 11: Correction process of subsidence factor.

the interface subsidence factor $q_{j}$ can be obtained from Figure 11 as follows:

$$
q_{j}= \begin{cases}0.80 \sim 1.00 & \text { soft lithology } \\ 0.65 \sim 0.85 & \text { medium-hard lithology } H_{s} \leq 1.2 H_{j}, \\ 0.40 \sim 0.65 & \text { hard lithology }\end{cases}
$$

$q_{j}=\left\{\begin{array}{ll}0.75 \sim 1.00 & \text { soft lithology } \\ 0.65 \sim 0.75 & \text { medium-hard, hardlithology }\end{array} 1.2 H_{j}<H_{s} \leq 2.0 H_{j}\right.$,

$q_{j}=0.80-1.00$ soft, medium-hard, hard lithology $H_{s}>2.0 H_{j}$.

4.3.2. For Surface. According to formula (17), to calculate the surface subsidence factor, we need to know the value of $q_{j}, k_{s}$, and $n$. Use formulas (18)-(20) to determine $q_{j}$ and formula (16) to calculate $n$. Generally speaking, $k_{s}$ is variety in different mine areas and does not suffer the effect of dip angle of coal seam and the rock lithology. For convenience in use, the theory lookup table calculated from formula (17) is shown in Table 3.

From Table 3, we can get the relevant data and calculate the surface subsidence factor.

4.4. Application Scope. The application of this method is limited. When the movement of the strata above the gob is only affected by self-weight and overburden pressure, the larger the thickness ratio, the higher the accuracy of parameter inversion. However, when a place has a wide range of geological structures (e.g., faults and folds) or geological events (e.g.,
TABLE 3: Lookup table of theoretical value of $k_{s}$ and $q_{s} / q_{j}$.

\begin{tabular}{lllllllllll}
\hline$n$ & & & & & & & & & & \\
$q_{s} / q_{j}$ & 50 & 100 & 150 & 200 & 250 & 300 & 350 & 400 & 450 & 500 \\
$k_{s}$ & & & & & & & & & & \\
\hline 0.995 & 1.28 & 1.65 & 2.12 & 2.73 & 3.50 & 4.50 & 5.78 & 7.43 & 9.54 & 12.26 \\
0.996 & 1.22 & 1.49 & 1.82 & 2.23 & 2.72 & 3.33 & 4.07 & 4.97 & 6.07 & 7.42 \\
0.997 & 1.16 & 1.35 & 1.57 & 1.82 & 2.12 & 2.46 & 2.86 & 3.33 & 3.87 & 4.49 \\
0.998 & 1.11 & 1.22 & 1.35 & 1.49 & 1.65 & 1.82 & 2.02 & 2.23 & 2.46 & 2.72 \\
0.999 & 1.05 & 1.11 & 1.16 & 1.22 & 1.28 & 1.35 & 1.42 & 1.49 & 1.57 & 1.65 \\
1.000 & 1.00 & 1.00 & 1.00 & 1.00 & 1.00 & 1.00 & 1.00 & 1.00 & 1.00 & 1.00 \\
1.001 & 0.95 & 0.90 & 0.86 & 0.82 & 0.78 & 0.74 & 0.70 & 0.67 & 0.64 & 0.61 \\
1.002 & 0.90 & 0.82 & 0.74 & 0.67 & 0.61 & 0.55 & 0.50 & 0.45 & 0.41 & 0.37 \\
1.003 & 0.86 & 0.74 & 0.64 & 0.55 & 0.47 & 0.41 & 0.35 & 0.30 & 0.26 & 0.22 \\
1.004 & 0.82 & 0.67 & 0.55 & 0.45 & 0.37 & 0.30 & 0.25 & 0.20 & 0.17 & 0.14 \\
1.005 & 0.78 & 0.61 & 0.47 & 0.37 & 0.29 & 0.22 & 0.17 & 0.14 & 0.11 & 0.08 \\
1.006 & 0.74 & 0.55 & 0.41 & 0.30 & 0.22 & 0.17 & 0.12 & 0.09 & 0.07 & 0.05 \\
1.007 & 0.71 & 0.50 & 0.35 & 0.25 & 0.17 & 0.12 & 0.09 & 0.06 & 0.04 & 0.03 \\
1.008 & 0.67 & 0.45 & 0.30 & 0.20 & 0.14 & 0.09 & 0.06 & 0.04 & 0.03 & 0.02 \\
1.009 & 0.64 & 0.41 & 0.26 & 0.17 & 0.11 & 0.07 & 0.04 & 0.03 & 0.02 & 0.01 \\
1.010 & 0.61 & 0.37 & 0.22 & 0.14 & 0.08 & 0.05 & 0.03 & 0.02 & 0.01 & 0.01 \\
\hline
\end{tabular}

earthquakes), the subsidence boundary shape model is unsuitable.

\section{Case Study}

The rock lithology of Bai Shan colliery in Huai Bei mine area is medium hard. The thickness of unconsolidated layer and the bedrock is $145 \mathrm{~m}$ and $64 \mathrm{~m}$, respectively. The coal seam thickness is $2.1 \mathrm{~m}$, and the dip angel of coal seam is $10^{\circ}$. The strike length of the workface is $500 \mathrm{~m}$, and the tendency length is $175 \mathrm{~m}$. The measured surface subsidence factor is 1.25 . 
TABLE 4: The calculated value of $1 / k_{s}^{82}$ and $q_{s} / q_{j}$.

\begin{tabular}{lcccc}
\hline$k_{s}$ & $1 / k_{s}^{82}$ & $n=50$ & $\begin{array}{c}q_{s} / q_{j} \\
n=82\end{array}$ & $n=100$ \\
\hline 0.995 & 1.5084 & 1.28 & 1.5168 & 1.65 \\
0.996 & 1.3891 & 1.22 & 1.4528 & 1.49 \\
0.997 & 1.2794 & 1.16 & 1.4016 & 1.35 \\
0.998 & 1.1784 & 1.11 & 1.3504 & 1.22 \\
0.999 & 1.0855 & 1.05 & 1.3184 & 1.11 \\
1.000 & 1.0855 & 1.00 & 1.28 & 1.00 \\
1.001 & 0.9213 & 0.95 & 1.248 & 0.90 \\
1.002 & 0.8489 & 0.90 & 1.2288 & 0.82 \\
1.003 & 0.7822 & 0.86 & 1.2032 & 0.74 \\
1.004 & 0.7208 & 0.82 & 1.184 & 0.67 \\
1.005 & 0.6643 & 0.78 & 1.1712 & 0.61 \\
1.006 & 0.6123 & 0.74 & 1.1584 & 0.55 \\
1.007 & 0.5644 & 0.71 & 1.1456 & 0.50 \\
1.008 & 0.5203 & 0.67 & 1.1392 & 0.45 \\
1.009 & 0.4796 & 0.64 & 1.1328 & 0.41 \\
1.010 & 0.4422 & 0.61 & 1.1264 & 0.37 \\
\hline
\end{tabular}

Based on the geological and mining condition, $H_{s} / H_{j}=$ 2.3 and $H_{s}>2.0 H_{j}$. According to formula (20), the interface subsidence factor is as follows:

$$
q_{j}=0.85
$$

Compress times $n$ :

$$
\begin{gathered}
n=\frac{H_{s}}{m q_{j} \cos \alpha}=\frac{145}{2.1 * 0.85 * \cos 10^{\circ}}=82, \\
\frac{q_{s}}{q_{j}}=\frac{1}{k_{s}^{82}} .
\end{gathered}
$$

Combined with Table 4 , the value of $q_{s} / q_{j}$ can be obtained by linear interpolation when $n=82$. In addition, the value of $1 / k_{s}^{82}$ is calculated by $k_{s}$. The values of both are shown in Table 4. According to formula (20), the two should be equal. By searching Table 4, we can see that when $k_{s}=1$, the two are basically equal. Therefore, the unconsolidated layer subsidence correction factor $k_{s}$ of Bai Shan colliery can be obtained, $k_{s}=0.995 . q_{s}$ is greater than $q_{j}$. It is stated that the surface subsidence aggravates because of the aquifer water loss and soil secondary consolidation.

Correspondingly, the value of $q_{s} / q_{j}$ is 1.5168 . Then, the calculated surface subsidence coefficient is

$$
q_{s c}=1.5168 * q_{j}=1.5168 * 0.85=1.29 .
$$

To evaluate the prediction precision, the relative error is used. The relative error is

$$
f=\frac{\left|q_{s a}-q_{s c}\right|}{q_{s a}},
$$

where $f$ is the relative error, $q_{s a}$ is the actual surface subsidence factor, and $q_{s c}$ is the calculated surface subsidence factor.

Bring in the value and calculate the relative error.

$$
f=\frac{\left|q_{s a}-q_{s c}\right|}{q_{s a}}=\frac{|1.25-1.29|}{1.25}=5 \% .
$$

The results show that the relative error is less than $10 \%$, which can meet the engineering requirements and can better predict the subsidence of overburden rock.

\section{Conclusions}

(1) This paper presents an inversion method of subsidence based on geological conditions. By using this method, the case that the surface subsidence is greater than the mining thickness can be inverted, which is not available in other methods

(2) Numerical simulation is used to reveal the variation law of surface mining-induced subsidence under different lithology and thickness ratio. For soft rock, the surface subsidence decreases approximately linearly with the thickness ratio increase of the unconsolidated layer to bedrock. However, for hard or medium-hard rock, the surface subsidence undergoes three proportional sections, first increases, then decreases, and finally increases with the thickness ratio increase of the unconsolidated layer to bedrock

(3) Based on the theory that the rock strata space can be completely compressed gradually, from the perspective of lithology, we have revealed the mechanism of the above laws

(4) The case study of this inversion method has been carried out. The results show that the inversion effect is good, and the relative error is only $5 \%$

\section{Data Availability}

The data used to support the findings of this study are available from the corresponding author upon request.

\section{Conflicts of Interest}

The authors declare that there is no conflict of interest regarding the publication of this paper.

\section{Acknowledgments}

This research work has been supported by the National Natural Science Foundation of China (50974122 and U1810203), the Specialized Research Fund for the Doctoral Program of Higher Education of China (20110023110014), the Key Scientific Research Projects of Higher Education Institutions 
in Henan Province (20A440005), the Youth Backbone Teacher Support Program of Henan Polytechnic University (2019XQG-07), the Fundamental Research Funds for the Universities of Henan Province (NSFRF200314), the Henan Scientific and Technological Project (212102310012), the Science and Technology Cooperative Planning of Guizhou Province (LH [2017]097), and the High-Level Talents Fund of Guizhou University of Engineering Science (G2015005). All those financial supports are gratefully acknowledged.

\section{References}

[1] S. Sinha, R. N. Bhattacharya, and R. Banerjee, "Surface iron ore mining in eastern India and local level sustainability," Resources Policy, vol. 32, no. 1-2, pp. 57-68, 2007.

[2] P. R. Helm, C. T. Davie, and S. Glendinning, "Numerical modelling of shallow abandoned mine working subsidence affecting transport infrastructure," Engineering Geology, vol. 154, pp. 6-19, 2013.

[3] P. Hadi, Y. B. Alireza, and N. Mehdi, "Impact of ground surface subsidence due to underground mining on surface infrastructure: the case of the Anomaly No. 12 Sechahun, Iran," Environmental Earth Sciences, vol. 78, p. 409, 2019.

[4] Z. Liu, B. Cui, Y. Liang, H. Guo, and Y. Li, "Study on foundation deformation of buildings in mining subsidence area and surface subsidence prediction," Geotechnical and Geological Engineering, vol. 37, no. 3, pp. 1755-1764, 2019.

[5] J. Zhang and L. Chong, "The discussion of the surface and building deformation in the coal mining subsidence area," Shanxi Architecture, vol. 38, no. 9, pp. 83-84, 2012.

[6] X. M. Cui, Y. G. Gao, and D. B. Yuan, "Sudden surface collapse disasters caused by shallow partial mining in Datong coalfield, China," Natural Hazards, vol. 74, no. 2, pp. 911-929, 2014.

[7] F. G. Bell, T. R. Stacey, and D. D. Genske, "Mining subsidence and its effect on the environment: some differing examples," Environmental Geology, vol. 40, no. 1-2, pp. 135-152, 2000.

[8] S. Saha, S. K. Pattanayak, E. O. Sills, and A. K. Singha, "Undermining health: environmental justice and mining in India," Health \& Place, vol. 17, no. 1, pp. 140-148, 2011.

[9] L. M. Fan, X. D. Ma, and R. J. Ji, “The progress of research engineering practice of water-preserved coal mining in western eco-environment frangible area," Journal of China Coal Society, vol. 40, no. 8, pp. 1711-1717, 2015.

[10] Z. Jinhai, J. Ning, Y. Liming, and B. Liyang, "The effects of mining subsidence and drainage improvements on a waterlogged area," Bulletin of Engineering Geology and the Environment, vol. 78, no. 5, pp. 3815-3831, 2019.

[11] J. J. Chen, Y. F. Zou, and W. B. Guo, "Study on the relationship between subsidence factor and mining degree under a thick alluvium stratum," Journal of Mining and Safety Engineering, vol. 29, no. 2, pp. 250-254, 2012.

[12] J. Ju and J. Xu, "Surface stepped subsidence related to top-coal caving longwall mining of extremely thick coal seam under shallow cover," International Journal of Rock Mechanics and Mining Sciences, vol. 78, pp. 27-35, 2015.

[13] J. Liu, X. Liang, Y. Xue, K. Yao, and Y. Fu, "Numerical evaluation on multiphase flow and heat transfer during thermal stimulation enhanced shale gas recovery," Applied Thermal Engineering, vol. 178, article 115554, 2020.

[14] Q. Qu, J. Xu, R. Wu, W. Qin, and G. Hu, "Three-zone characterisation of coupled strata and gas behaviour in multi-seam mining," International Journal of Rock Mechanics and Mining Sciences, vol. 78, pp. 91-98, 2015.

[15] L. Chen, X. Feng, W. Xie, and D. Xu, "Prediction of waterinrush risk areas in process of mining under the unconsolidated and confined aquifer: a case study from the Qidong coal mine in China," Environmental Earth Sciences, vol. 78, no. 8, p. 706, 2016.

[16] W. Yan, H. Dai, and J. Chen, "Surface crack and sand inrush disaster induced by high-strength mining: example from the Shendong coal field, China," Geosciences Journal, vol. 22, no. 2, pp. 347-357, 2018.

[17] C. Q. Ma, H. Z. Li, and P. P. Zhang, "Subsidence prediction method of solid backfilling mining with different filling ratios under thick unconsolidated layers," Arabian Journal of Geosciences, vol. 10, no. 78, pp. 1-12, 2017.

[18] G. Ren, G. Li, and M. Kulessa, "Application of a generalised influence function method for subsidence prediction in multi-seam longwall extraction," Geotechnical and Geological Engineering, vol. 32, no. 4, pp. 1123-1131, 2014.

[19] W. T. Yan, J. J. Chen, and Y. G. Yan, “A new model for predicting surface mining subsidence: the improved lognormal function model," Geosciences Journal, vol. 23, no. 1, pp. 165-174, 2019.

[20] W. Liu, J. Xu, W. Zhu, and S. Wang, "A novel short-wall caving zone backfilling technique for controlling mining subsidence," Energy Science \& Engineering, vol. 7, no. 5, pp. 1-14, 2019.

[21] D. Y. Xuan and J. L. Xu, "Grout injection into bed separation to control surface subsidence during longwall mining under villages: case study of Liudian coal mine, China," Natural Hazards, vol. 73, no. 2, pp. 883-906, 2014.

[22] J. Z. Wang, Y. S. Li, X. Zhou, L. Wu, and S. Wei, "Ground movement caused by mining under thick alluvium," Journal of China Coal Society, vol. 22, no. 1, pp. 18-21, 1997. 